\title{
O que vai pelos cinemas: a crítica cinematográfica e a construção das identidades
}

\section{What goes around on the movies: film criticism and the construction of identities}

\section{Paula Regina Puhl}

Professora no Programa de Pós-Graduação em Processos e Manifestaçoes Culturais da Universidade FEEVALE/RS/BR. paulapuhl@feevale.br

Cristina Ennes da Silva

Professora no Programa de Pós-graduação em Processos e Manifestaçōes Culturais da Universidade FEEVALE/RS/BR. crisennes@feevale.br

\begin{abstract}
RESUMO
O presente artigo apresenta e analisa a relação entre a crítica de cinema publicada em jornais impressos com a construção das identidades culturais de uma sociedade. Foi feito um estudo de caso a partir do Jornal O 5 de abril, primeiro semanário da cidade de Novo Hamburgo entre os anos de 1945 quando foi publicada a primeira crítica até 1950, ano em que a mesma foi extinta. As críticas cinematográficas eram guias para os leitores podendo inclusive influenciar na compreensão e no valor simbólico dado aos filmes. Estudar as colunas de crítica publicadas em meios de forte influência e circulação em um município colabora para compreender a leitura/interpretação de um pensamento representativo sobre uma época em que a experiência cinematográfica era parte do cotidiano de diversas sociedades.
\end{abstract}

Palavras-chave: crítica cinematográfica; imprensa; identidades

\section{ABSTRACT}

This article analyzes the relationship between film criticism published in newspapers with the construction of cultural identities in a society. A case study was undertaken from the paper $O 5$ de abril, the first weekly newspaper in the city of Novo Hamburgo between the years 1945 when the first film criticism was published until 1950, the year in which it was extinguished. The film criticism texts were guides for readers and may even have influenced the understanding and symbolic value given to films. Studying the film criticism published in media with strong influence and circulation in a city, contributes to understand the reading/ interpretation of a representative thinking about a time when the movie experience was part of everyday life for many societies. KeYwords: film criticism; press; identities 
$\mathrm{O}$

interesse que o cinema desperta na sociedade gerou uma ampla e diversificada historiografia que conta com múltiplas abordagens tanto regionais como nacionais, como exemplo, destacamos o estudo analítico e questionador sobre a história do cinema no Brasil de JeanClaude Bernardet (1995) e estudos focando regiões e cidades, discutindo as trajetórias históricas por meio do cinema e através dele, permitindo abordagens de questões urbanísticas e territoriais como de Jefferson Francisco Selbach (1999) e pesquisas sobre a sociabilidade do público nas salas desenvolvido por Alexandre Câmara Vale (2000).

A abordagem temática deste artigo refere-se a uma parcialidade de um projeto mais amplo intitulado, O processo de construção de identidades: um estudo sobre a influência do cinema em Novo Hamburgo iniciado em 2008.

\section{Os registros sobre cinema e os estudos sobre construção de identidades}

Neste enfoque de pesquisa preocupamo-nos em analisar os registros sobre a temática Cinema na Imprensa escrita entre os anos de 1927 e 1962, no primeiro semanário da cidade, considerando as múltiplas formas de apresentação da informação que apresentaram relação com o tema Cinema. Já foram realizadas as seguintes investigações: a influência do cinema em relação com a Segunda Guerra Mundial, a questão referente aos filmes seriados apresentados na cidade, o registro dos filmes de animação e dos filmes de terror.

Com o intuito de traçar um panorama crítico sobre o cenário cinematográfico e sua influência na construção das identidades a partir dos registros sobre filmes no jornal opta-se, nesse artigo, em analisar a inserção da crítica de cinema - denominamos "crítica" os textos encontrados no jornal que abordavam o conteúdo dos filmes e noticiavam as atividades ocorridas nas salas de cinema - sendo que não foi considerada a listagem da programação dos cinemas.

O período de análise para a composição deste artigo acompanha o surgimento da primeira coluna O que vai pelos cinemas, em 1945 até 1950, ano em que a mesma deixa de ser publicada. Para a realização dessas observações, foram pesquisadas todos exemplares do período, no total foram 264 edições, onde foram encontrados e fotografados 310 escritos relacionados a crítica de cinema. Esses dados serão estudados tendo como recorte cinco críticas para refletir de que forma a coluna pode ter colaborado na construção das identidades sociais e culturais dos hamburguenses ${ }^{1}$.

Destaca-se que este estudo tem como referencia um local (cidade de Novo Hamburgo ${ }^{2}$ ) e uma fonte específica (jornal $O 5$ de abril), entretanto essa pesquisa pode ser feita/aplicada em outras 
cidades/periódicos, visto que a cultura cinematográfica esteve no auge de sucesso e divulgação no Brasil nas décadas de 40 e 50 e por esse motivo, certamente foi fator determinante para a construção de identidades em diversas cidades que utilizavam o Cinema como uma prática de lazer, divertimento e como uma janela para o mundo exterior.

\section{Cinema como espaço social}

O cinema antes da televisão foi uma das mídias de maior alcance das massas e por isso a sua influência na construção da cultura. Diferente do rádio os filmes trouxeram para as salas de cinema a imagem de cenários, objetos e atores para perto da sociedade. A presença das salas de cinema e seus filmes aproximavam os continentes e os tornavam conhecidos de pessoas culturas que só seriam experienciadas mediadas pela grande tela.

Além dos filmes o ato de ir ao cinema se tornou um evento, principalmente nos primeiros cinqüenta anos no século XX, como coloca Turner (1997) antes mesmo do aparecimento dos primeiros aparelhos televisores, já existia o pensamento do cinema como uma prática social que envolvia toda uma preparação e fazia parte da vida e cultura de determinadas comunidades.

Seguindo o pensamento de Turner (1997) a cultura é um processo dinâmico que produz os comportamentos, as práticas, as instituições e os significados que constituem nossa existência social e os filmes podem ser considerados agentes culturais, já que as representações discursivas apresentadas por eles colaboram para dar sentido a um modo de vida a um pensamento de uma época.

Assim, o cinema é parte fundamental da construção e do reflexo da cultura da sociedade, pois é considerado uma prática social, já que gera seus significados por meio de sistemas como a linguagem cinematográfica que produz e reproduz os significados sociais podendo interferir diretamente na criação das identidades de seu público.

O espectador entende os sistemas próprios de significação das narrativas cinematográficas. Turner (1997) destaca que o cinema tem seus próprios códigos e convenções, que funcionam como regras para o espectador no momento de assistir um filme, e por esse motivo não se questiona o realismo nas cenas ou ainda já se presume o significado narrativo ao compreender os enquadramentos e a trilha sonora de acordo com o gênero cinematográfico.

No entanto mesmo apresentando uma gramática conhecida do espectador o cinema como linguagem visual oferece mais do que apenas a leitura preferencial ditada pelo seu roteiro, 
podendo receber diferentes interpretações de cada indivíduo. Essa ideia de uma leitura preferencial não se distingue totalmente da noção de um significado "verdadeiro". O texto ainda é visto como ditador máximo de suas leituras. O que se oferece é uma descrição "das diferentes leituras do mesmo texto". É importante reconhecer que, se acreditamos que o significado é até certo ponto indeterminado, então "diferentes leituras" de um filme na verdade produzirão "diferentes" filmes (Turner, 1997, p. 123).

Nessa discussão sobre as possíveis leituras da obra cinematográfica, surge um novo personagem externo à narrativa - o crítico de cinema e as suas colunas que podem interferir na compreensão, interpretação do indivíduo, desde que esse protagonista (o crítico) tenha legitimidade perante a sociedade que pertence e tenha espaço em um veículo respeitado pela sociedade para publicar os seus comentários.

\section{A crítica de cinema no Brasil}

Lunardelli (2008, p. 11) diz que a crítica de cinema trata sobre a "paixão de ver cinema, de pensar, de debater, de escrever sobre cinema. De dar sentido ao mundo e à vida através do cinema". A crítica situa-se assim em um trabalho de mediação entre a platéia e o filme, ou entre o filme e seus realizadores. Del Pozo tem sua própria definição sobre a crítica:

66 O trabalho do crítico é, primordialmente, o de conselheiro ou assessor do espectador. Sem entrar a fundo no conteúdo do filme, porque isso acabaria com o elemento surpresa ou pelo menos de novidade que constitui um de seus atrativos, dirige a atenção do futuro espectador para determinados aspectos do filme, tanto positivos como negativos, a fim de proporcionar uma vivência cinematográfica mais completa (Del Pozo, 1970, p. 16).

O surgimento da crítica data do século XIX, derivada das críticas de eventos culturais, como o teatro e festas, presentes nas publicações principalmente européias. O crescimento do cinema em nível mundial colaborou para o surgimento de novas pessoas interessadas em debater a nova mídia. A figura do crítico começa aos poucos a surgir, sendo boa parte responsabilidade do francês Andre Bazin (Lunardelli, 2008).

Lunardelli (2008) cita o artigo de Enéas Souza, Pensamento crítico de Bazin, onde o mesmo declara Andre Bazin como primeiro grande crítico de cinema. $\mathrm{O}$ francês nasceu no ano de 
1919 e morreu 40 anos depois, tornando-se a maior referência no universo da crítica cinematográfica.

A autora define a crítica como parte integrante do jornalismo opinativo e declara que até os anos 60, foi vista com a função de se dizer o que de "bom" o cinema tem para oferecer para espectadores que pouco se importam, no periodismo diário.

No Rio Grande do Sul, os primeiros movimentos envolvendo a crítica de cinema tem no nome de P. F. Gastal seu principal articulador. Nascido em Pelotas no ano de 1922, o garoto que era apaixonado por cinema tornou-se colunista do jornal Diário Popular, em 1941.

Enquanto Porto Alegre tinha P. F. Gastal como principal articulista de cinema, Novo Hamburgo irá apresentar apenas no ano de 1945, uma coluna que irá apresentar os primeiros elementos de crítica de cinema na cidade, no Jornal $O 5$ de abril.

A coluna $O$ que vai pelos cinemas começou a ser publicada no ano de 1945. Sem apresentar autor, a coluna debate os principais lançamentos da semana nas 4 salas de cinema da cidade, enfatizando as características positivas de cada produção, uma breve sinopse e sua repercussão nos cinemas do Brasil e do mundo. A coluna não fala sobre as produções menores ou mesmo relata os aspectos negativos dos filmes comentados. O que vai pelos cinemas teve 5 anos de duração, e após esse período, simplesmente deixou de ser publicada.

\section{O cinema e a imprensa em Novo Hamburgo}

Para analisar a construção das identidades dos hamburguenses a partir da inserção do cinema e da divulgação das criticas cinematográficas no jornal $O 5$ de abril é importante observar como grupos mantêm referenciais, que os diferenciam ou aproximam, ou ainda os faz parecer únicos, marcas de um território não demarcado, como o Vale do Sinos, que tem como referencial econômico o setor coureiro-calçadista. Para compreender as forças que atuam na formação de uma identidade, o que ela significa e a evolução histórica da conceituação do termo, buscam-se os esclarecimentos e problematizações do conceito de identidade em relação ao outro - a alteridade. Por essa razão esse artigo tem como premissa as idéias de Roger Chartier e Pierre Bourdieu utilizadas como suporte teórico para a análise.

O material a ser explorado são as críticas cinematográficas do Jornal $O 5$ de abril que nasce junto com a emancipação do município em 27 de Abril de 1927. O contexto da sua criação é situado no início dos anos 1920 quando a valorização do trabalho e do progresso são os valores 
fundamentais defendidos pelos hamburguenses. Assim nasce a ideia do principal órgão de comunicação local, do $\mathrm{O} 5$ de Abril. Sua história se inicia um dia após a confirmação oficial da emancipação do município de em 6 de abril de 1927 e fecha suas portas em 1962. Criado por um grupo que defendia o movimento emancipacionista em relação a São Leopoldo, cidade próxima, o nome foi escolhido em homenagem à data de emancipação do município.

É importante destacar que os textos presentes nos meios de comunicação de massa, por intermédio da articulação com a sociedade, reconfiguram o espaço social. Esse processo ocorre quando as questões das identidades culturais podem ser percebidas através dos discursos jornalísticos, a partir, por exemplo, dos jornais impressos. Esse movimento pôde ser visualizado nas páginas do jornal $\mathrm{O} 5$ de Abril, que no caso do município de Novo Hamburgo foi o primeiro meio de comunicação de massa voltado para a população local.

O nascimento e a permanência de um veículo de comunicação que busca atingir um elevado número da população acaba por destacar, ou ainda, agenciar determinados assuntos que geralmente influenciam a opinião pública. McCombs e Shaw, citados por Traquina (2001), advertem que a capacidade das mídias em influenciar a projeção dos acontecimentos na opinião pública confirma o seu papel na figuração da nossa realidade, isto é, "de um pseudo-ambiente, fabricado e montado quase completamente a partir dos mass midia" (McCombs; Shaw apud Traquina, 2001, p.14). Esse processo na cidade era feito pelo jornal $O 5$ de abril que para facilitar a informação para os moradores era escrito em português e alemão.

Já o surgimento das salas de cinema no município e a sua relação com a comunidade iniciou antes da existência do semanário. Em 1913, o senhor Adão Adolfo Schmitt alugou o salão de sua casa no bairro Hamburgo Velho para a projeção de filmes. Anos depois, Sara Lanzer, proprietária de uma casa de comércio e frequentadora assídua do cinema, com o capital obtido por um prêmio de loteria, mandou construir uma sala de projeções. Esta sala recebeu o nome de Cinema Central e, na década de 40, teve o nome trocado para Cine Aída.

Ainda na década de 1930, foi construído o Cinema Guarani em uma das principais vias da cidade pela empresa Jaeger \& Venturini Ltda. Na década de 1950, a mesma empresa construiu o Cine Lumière e, nos anos 1960, o Cine Avenida. Nesse período também já havia o Cine Theatro Carlos Gomes, que era propriedade da família Blankenheim.

Essa breve incursão sobre a relação entre o jornal local e o cinema no município tem como objetivo reconhecer que a construção das identidades do novo-hamburguês teve influência do 
cinema, principalmente por terem acesso às informações sobre cinema publicadas nas páginas do jornal.

Esse fato também foi verificado no artigo Lazer e sociabilidade em Novo Hamburgo: no escurinho do cinema $a^{3}$, utilizando a história oral, os depoimentos comprovaram que o contato que a população tinha com os fatos nacionais e estrangeiros sobre moda, política, entre outros assuntos, era ilustrado por imagens através dos filmes de procedência na sua maioria internacional e alguns nacionais.

Já nesse artigo verificamos que além do contato direto com os filmes os depoentes também poderiam ser influenciados pela crítica, pelo aconselhamento sobre as películas que eram divulgadas no único jornal da cidade, já que as críticas apresentavam conselhos, explicações e ainda emitiam juízo de valor sobre os filmes que entravam em cartaz na cidade.

As salas de cinema da cidade e os filmes exibidos possuíam como intermediário as críticas de cinema que eram influentes por estarem sendo veiculadas no único meio de comunicação impresso local. Ou seja, esse trinômio salas/filmes/crítica certamente teve influência na construção das identidades culturais já que não havia a concorrência com outros meios de comunicação.

\section{A crítica cinematográfica e a construção da identidade cultural}

Para Cuche (1998) o conceito de Cultura está intimamente ligado ao de Identidade, no entanto são diferentes, mas possuem uma grande ligação. A Cultura pode existir sem consciência de identidade, mas as estratégias de identidade podem modificar uma cultura caso esteja associada a oposições simbólicas. Nesse estudo entende-se por identidade a interação entre o indivíduo e o seu meio ambiente social. Acredita-se que é o reconhecimento identitário do indivíduo que o agrega a um grupo e o diferencia de outro, e nesse artigo essa diferença será nomeada de identidade cultural, seguindo as ideias de Cuche (1998). Essa identidade cultural é alimentada e legitimada pelo poder simbólico das representações discursivas. Dessa forma recorre-se ao pensamento de Bourdieu (1998) ao considerar o poder dos símbolos como instrumentos de integração social, sendo que esses são apresentados e potencializados junto ao público nas críticas cinematográficas. Essas representações fazem parte do imaginário social citado por Chartier (1998) que atua também na formação das identidades. 


\section{O que vai pelos cinemas: as boas vindas ao espetáculo cinematográfico}

Conforme referenciado anteriormente, neste mesmo texto, a coluna $O$ que vai pelos cinemas começou a ser publicada no ano de 1945. Sem apresentar autor, a coluna debate os principais lançamentos da semana nas quatro salas de cinema da cidade, enfatizando as características de cada produção, uma breve sinopse e sua repercussão nos cinemas do Brasil e do mundo.

Apesar disso, a coluna não fala sobre as produções menores ou mesmo aspectos negativos dos filmes comentados. O que vai pelos cinemas teve cinco anos de duração, e após esse período, simplesmente deixou de ser publicada. Serão analisadas cinco críticas e a fim de ressaltar os principais trechos da coluna. Essas falas estarão escritas em itálico e entre aspas, respeitando a escrita da época da publicação.

Na crítica publicada em 14 de junho de 1945 são comentados os filmes Mulheres com asas (sem data da produção) e Bonita como Nunca de (1942). É utilizada a página inteira do jornal e no meio em destaque o cartaz do filme Bonita como nunca, com a foto de Fred Astaire e Rita Hayworth, que trata de um romance entre uma menina de família argentina abastada que se apaixona por um dançarino americano que está procurando por trabalho ${ }^{4}$. Os trechos que chamam a atenção são sobre as questões femininas colocadas em frases como: "Na tela o film Mulheres com asas, um dos bons films da atualidade, uma verdadeira exaltação a mulher", já a respeito da película com Hayworth a coluna chama a atenção "para uma comédia cintilante de espírito e repleta de improvisos".

Mas o destaque nessa publicação versa sobre um acontecimento diferente. Na sala de cinema alem da veiculação do filme iria acontecer a apresentação de um produção do teatro local, segundo a crítica seria "um espetáculo de tela e palco". Essa aproximação é vista pela frase: "No palco Peró Borges e Estelita Bell com números de esquetes e canto, muito agradaram à numerosa platéia que os assistia e que soube premiar com seus aplausos o desempenho impecável da festejada dupla".

Esse comentário reforça a necessidade de firmar o sentimento de pertença a um determinado grupo que está representado por símbolos, no caso a apresentação cultural em um local que está mais ligado a divulgação de símbolos exteriores a comunidade. Segundo Bourdieu, em O Poder Simbólico (1998, p. 10), os símbolos são os instrumentos da integração social. Para o autor os instrumentos de conhecimento e de comunicação tornam possível o consensus acerca do sentido 
do mundo social e colabora para construir uma análise de identidade e representação sobre a ideia de região, pois, para ele, realidades são representações, que "dependem do conhecimento e do reconhecimento" (Bourdieu, 1998, p. 108).

Na crítica de 06 de março de 1946 o filme Laura (1944) é abordado, assim como na crítica anterior é apresentada a sinopse da obra com o uso de vários adjetivos como "uma heroína preciosa", referente a protagonista Dana Andrews, e um "gala ousado e resoluto", "um vilão diferente de todos os outros", protagonizados por Gene Tierney, Clifton Webb 5 . No entanto é no final do texto que há um recado para o público da cidade "Laura o sofisticado drama psicológico que o Carlos Gomes (o Cinema) vai apresentar amanhã e domingo aos seus frequentadores". Mais uma vez, o enunciado faz com que os leitores tenham a sensação de inclusão. Sob a ótica de Bourdieu, o fazer reconhecer e ser reconhecido sem o emprego e sem o entendimento de arbitrariedade são as condições básicas de apresentação do poder simbólico, ou, nas suas palavras:

66 O poder simbólico como poder constituir o dado pela enunciação, de fazer ver e fazer crer, de confirmar ou de transformar a visão do mundo e, deste modo, a acção sobre o mundo, portanto o mundo; poder quase mágico que permite obter o equivalente daquilo que é obtida pela força (física ou economica), graças ao efeito específico de mobilização, só se exerce se for reconhecido, quer dizer, ignorado como arbitrário (Bourdieu, 1998, p.14).

Essa tentativa de aproximar os filmes da comunidade também foi vista na crítica publicada em 17 de dezembro de 1945 a respeito da película Sempre Tua de 19436 , quando é dito: “Nenhum cartaz vem sendo tão ansiosamente esperado quanto Sempre Tua que o Carlos Gomes, apresentará, sábado e domingo, à sua distinta e numerosa platéia" e "filme entrecortado de cenas alegres, umas, capazes outras de fazer brotar lágrimas nos olhos dos espectadores". Esses trechos guiam os leitores do jornal, pois valorizam a presença deles ao dizer que mesmo sendo numerosa a plateia ela é distinta, já na segunda fala é atestado um comportamento. A crítica permite as expressões de riso e choro. Esses fatores são importantes em uma cidade que, na época, tinha na sua maioria descendentes de alemães, povo conhecido pela frieza e dedicação ao trabalho e não tanto por expressar as suas emoções.

Essas propriedades simbólicas, segundo Bourdieu, são passíveis de serem usadas de acordo com os interesses materiais e simbólicos que tem o portador destas propriedades, no caso aqui 
a voz do crítico, ou seja, as ideias dele podem ser utilizadas para atingir determinado fim, no sentido de construir ou "incluir no real a representação do real", ou o que chama "a luta das representações", a partir de "imagens mentais e representações sociais" no sentido de reorganizar ou modificar as representações sociais já existentes (Bourdieu, 1998, p. 112-113).

O surgimento de Novo Hamburgo, conforme Petry (1944) está intimamente ligado ao projeto imperial brasileiro de ocupação da região meridional do país, com população européia leal ao Imperador e a Coroa. Dentro desse processo, desembarcaram no Rio Grande do Sul, a partir de 1824, sucessivas levas de imigrantes de origem germânica, que foram se estabelecendo em várias regiões do Estado ${ }^{3}$.

A criação da cidade foi potencializada pela criação da linha férrea, um dos mais importantes impulsionadores do desenvolvimento das colônias germânicas no Vale dos Sinos. De acordo com Petry (1944) essa facilidade de escoamento da produção colonial e a qualificação para o trabalho artesanal dos povoadores de origem germânica, apoiado pela existência de couro e derivados do couro como matéria prima, fez desenvolver-se a indústria coureiro - calçadista. Acredita-se que pela força da descendência dessa comunidade os cinemas também possuíam na sua programação filmes de origem alemã como mostra a crítica publicada em 6 de setembro de 1946 sobre o filme Música de Sonho (Traumusik) de 1940. Esse comentário foi o primeiro a tratar da exibição do primeiro filme alemão após a $2^{a}$ Guerra Mundial, em Novo Hamburgo. De acordo com o texto, o filme todo cantado e falado em alemão é o primeiro filme a ser liberado pelo governo federal para exibição nos cinemas.

O autor do texto ressalta as grandes interpretações artísticas e musicais, além dos números de dança que chama a atenção na projeção, mas o fato mais curioso desse artigo pode ser visto na semana seguinte, quando o jornal publica um pequeno parágrafo sobre a repercussão do filme alemão na cidade.

De acordo com o autor "foi uma das maiores lotações do ano", a película, que conta com um elenco de atores alemães ${ }^{7}$ causou uma inesperada e curiosa "enchente" de espectadores no Cine Carlos Gomes, impulsionada pela crítica publicada na semana anterior, visto que o filme havia sido exibido uma semana antes no Cine Aida. Para finalizar o artigo assegura: "Esta produção estará em definitivas exibições nesta cidade".

Após a análise das colunas que mais exaltavam os filmes e a relação destes com a população, foi encontrado pela pesquisa um texto sobre um filme, em 5 de agosto de 1948, denominada crônica 
de cinema. Diferente das costumeiras fotos de cartazes e comentários relacionados à produção na coluna o que vai pelos cinemas, são traçados comentários referentes a modo de vida hamburguense e o que se pode aprender com o conteúdo do filme.

Inaugurando a coluna é comentada a película Tributos Sexuais, o autor traça um paralelo entre as perigosas doenças venéreas que podem ser muito facilmente transmitidas com atos sexuais ilícitos, por pessoas com vidas desregradas. Ele ainda culpa a mídia pela indecência em suas publicações e por incentivar tais atos libidinosos. Ao final o autor alerta "recomenda-se aos pais e educadores assistirem essê filme, nesta hora que até publicações, com responsabilidade, tornam-se veículos da imoralidade, da indecência e do despresos públicos".

O autor chama a atenção por oferecer um ponto de vista crítico em relação a um tema que a seu ver era de preocupação pública e, através de um filme, sua discussão pode ser intensificada e assim, conscientizar a população sobre esses perigos. Esse imaginário social na construção de representações que atuam na formação de identidades é um processo analisado por Chartier (1991), que entende a necessidade de abandonar velhos paradigmas de uma história globalizante para buscar entender as sociedades e os seus funcionamentos a partir das suas particularidades. Segundo Chartier é necessário "penetrar" nas "relações" e "tensões" da sociedade, numa ação que tem como pressuposto a inexistência de "prática ou estrutura que não seja produzida pelas representações", sob esse viés a análise das críticas possibilitam entender a partir das palavras do autor das colunas como a sociedade estava vivendo aquele momento histórico. $\mathrm{E}$ ao falar de cinema um produto global difundido principalmente pela cultura de massa em um meio informativo como o jornal temos uma ideia do imaginário social da cidade. Para Chartier,

66 Quem pensa a construção das identidades sociais como resultado sempre de uma relação de força entre as representações impostas pelos que detêm o poder de classificar e de nomear e a definição, de aceitação ou de resistência, que cada comunidade produz de si mesma, outra que considera o recorte social objetivado como a tradução do crédito conferido à representação que cada grupo dá de si mesmo, logo a sua capacidade de fazer reconhecer a sua existência a partir de uma demonstração de unidade (Chartier, 1991. p. 183).

Apesar de ter sido encontrado mais textos com comentários positivos nas colunas, foi observado o cuidado especial nos textos escritos pelo autor ou autores, o que mostra que 
esses "críticos" tinham conhecimento suficiente até mesmo para inserir pequenos comentários subentendidos pelos cinéfilos.

Conforme Chartier a identidade que cada sociedade tem ou constrói de si passa pelo seu entendimento e pela sua própria aceitação desta identidade, construída por práticas que derivam de representações coletivas. Essas representações como o cinema (consideramos aqui todas as suas manifestações) têm capacidade de seduzir sem o emprego de força, são construções que levam à construção de uma realidade de um imaginário social.

\section{Considerações finais}

A história de Novo Hamburgo atesta o interesse da cidade pelo ato de ir aos cinemas. Durante 20 anos, a cidade manteve quatro salas de cinema, oferecendo uma variada programação que contava com a presença sempre freqüente de sua população. Além disso, tendo o jornal como principal fonte de informação de sua época, reforçava sua importância como formador de opiniões, principalmente no que diz respeito a cinema.

A crítica de cinema no jornal $O 5$ de Abril pode não ser tão impactante ou controversa quanto outros veículos que já publicavam esse tipo de texto no estado, mas ressaltava as principais qualidades de cada produção, com comentários curiosos e auxiliando os leitores do jornal a compreender melhor a produção ou prestar atenção em detalhes que pudessem fugir em uma simples ida ao cinema.

Nos registros históricos coletados nota-se a importância da crítica em relação à identidade hamburguense. As raízes germânicas se manifestaram claramente na exibição do filme Música de Sonho, que após crítica publicada pelo jornal fez com que a maioria da população comparece nas sessões do primeiro filme alemão exibido no Brasil, um ano após o fim da $2^{a}$ Guerra Mundial.

A crítica de cinema também oferece a visão dos costumes morais da cidade nos anos 40, como analisado na Crônica de Cinema, no filme Tributos Sexuais. A opinião do escritor reflete a moral que a sociedade tentava manter utilizando uma produção cinematográfica como ponto de análise para o comportamento da população hamburguense.

A coluna $O$ que vai pelos cinemas precedeu em 15 anos a produção de crítica de cinema especializada nos semanários de Novo Hamburgo, sendo que apenas na década de 60 essa atividade será retomada em outros jornais da cidade, juntamente com a criação de clubes de cinema ligados a religião católica, o que expressa outro direcionamento, onde a crítica não 
exaltava mais só o espetáculo, mas a uma análise mais intelectual, conforme aponta os estudo feitos por Puhl (2009).

Por fim, ao analisar os 310 registros impressos relacionados à crítica cinematográfica do jornal O 5 de abril, acredita-se que a população hamburguense entre os anos de 45 e 50, apresentou interesse nas opiniões veiculadas, vindo a justificar a duração da coluna publicada semanalmente e nos resultados demonstrados na presença do público em sessões indicadas. Sob essa perspectiva, tanto o Cinema, quanto a crítica por suas características técnicas e seu valor cultural podem ser considerados elementos influentes na construção das identidades de uma população como a de Novo Hamburgo, que ainda não possuía televisores e via nas salas de cinema um espaço tanto de convivência, quanto uma janela para outras culturas, hábitos e costumes.

\section{NOTAS}

1 Essa pesquisa contou com a participação do bolsista de IC da Feevale Misael Lima responsável pela coleta de dados e parte da análise dos dados.

2 Cidade da região metropolitana de Porto Alegre, capital do estado do Rio Grande do Sul, Brasil.

3 Texto publicado na Revista Esboços v. 16, n. 21, p. 41-68 - UFSC. Disponível em: <http://www.periodicos.ufsc.br/index.php/ esbocos/article/view/6344> Acesso em: 12 out 2009.

4 Informações sobre o filme retiradas do site: <http://www.imdb.com/title/tt0035583/>. Acesso em: 10 mar. 2011.

5 Informações sobre o filme retiradas do site: <http://www.imdb.com/title/tt0037008/>. Acesso em: 10 mar. 2011.

6 Informações sobre o filme retiradas do site: <http://www.imdb.com/title/tt0035631/>. Acesso em: 10 mar. 2011.

7 Informações sobre o filme retiradas do site: http://www.imdb.com/title/tt0033182/. Acesso em: 10 mar. 2011.

\section{REFERÊNCIAS}

BEHREND, Martin Herz. O 5 de Abril. Porto Alegre: Metrópole Ind. Gráfica, 2002.

BERNARDET, Jean-Claude. Historiografia Clássica do Cinema Brasileiro. São Paulo: Annablume, 1995.

BOURDIEU, Pierre. O poder simbólico. Lisboa: Bertrand/Difel, 1998.

CHARTIER, Roger. A História Cultural entre Práticas e Representações. Lisboa: Difel, 1990.

. O mundo como representação. Estud. av., São Paulo, v. 5, n. 11, 1991. Disponível:<http://www.scielo.br/scielo. php?script=sci_arttext\&pid=S0103-40141991000100010\&lng=en\&nrm=iso $>$. Acesso em: 06 mai 2007.

CUCHE, Denys. A noção de cultura nas ciências sociais. Bauru, SP: EDUSC, 2002. 
DEL POZO, Mariano. El cine y su crítica. Pamplona Ediciones Universidad de Navarra, 1970.

LUNARDELLI, Fatimarlei. A crítica de cinema em Porto Alegre na década de 1960. Porto Alegre, RS: UFRGS, 2008. PETRY, Leopoldo. O município de Novo Hamburgo: monografia. São Leopoldo, RS: Rotermund, 1959.

PUHL, Paula Regina. Uma bênção apostólica? Cinema e religião na construção das identidades em Novo Hamburgo. Revista Estudos de Religião, PUC-São Paulo., v. 23, n. 37, 34-52, jul./dez. 2009.

SELBACH, Jefferson Francisco. Novo Hamburgo 1927-1997: os espaços de sociabilidade na gangorra da modernidade. 1999. 416 f. Dissertação (Mestrado em Planejamento Urbano e Regional) - Faculdade de Arquitetura, UFRGS, Porto Alegre, 1999

SILVA, Cristina Ennes da; PUHL, Paula Regina; STRÖHER, Carlos Eduardo. Lazer e sociabilidade em Novo Hamburgo: no escurinho do cinema. REVISTA ESBOÇOS, v. 16, n. 21, p. 41-68. Disponível em: <http://www.periodicos.ufsc.br/ index.php/esbocos/article/view/6344>. Acesso em: 14 maio 2009.

TRAQUINA, Nelson. O Estudo do jornalismo no século XX. São Leopoldo, RS: Universidade do Vale do Rio dos Sinos, 2001.

TURNER, Graeme. Cinema como prática social. São Paulo, SP: Summus, 1997.

VALE, Alexandre F. Câmara. No escurinho do cinema: cenas de um público implícito. São Paulo: Annablume, 2000. 